\title{
PWM Speed Control of ACSingle Phase Induction Motor Using MCUSeries Combined With TRIACTechnology
}

\author{
R.Khan and M.M.S. Riyadh
}

\begin{abstract}
Single phase induction motor has been used widely in discipline industry and household where a simple motor starter can't let vary speed in starting and also running with mechanical load. This paper introduces a method for controlling the speed of an $\mathrm{AC}$ single phase induction motor. Combination of micro controller unit \& TRIAC has been used. A single phase induction motor adjustable speed control is implemented with hardware setup and software program. The main feature used in PIC17C756 microcontroller to control speed is pulse width modulation technique. Voltage drop across two terminals of TRIAC MT1 and MT2 is controlled with its gate voltage. Gate is controlled by DIAC and its input is controlled by an $\mathrm{R}-\mathrm{C}$ triggering circuit. In triggering circuit variable resistor is used to vary TRIAC gate voltage through DIAC. DIAC gate voltage, TRIAC input voltage and output voltage are also simulated by "Electronic Workbench" software. One chip and re-programmable ROM avoids nonlinearity and it can replace mechanical speed variation. Output voltage and capacity of the system can also be varied.
\end{abstract}

Index Terms-Pulse width modulation, micro controller unit, triode for alternating current, diode for alternating current, silicon controlled rectifier, metal oxide semiconductor field effect transistor.

\section{INTRODUCTION}

An induction or asynchronous motor is a type of $\mathrm{AC}$ motor where power is supplied to the rotor by means of electromagnetic induction, rather than by slip rings and commutators as in slip-ring AC motors [1]. Single phase induction motor is the most familiar of all electric motors \& they are similar to a 3-phase squirrel cage induction motor. It has a squirrel-cage rotor identical to a 3-phase motor and a single phase winding on the stator [2].

There are several methods for controlling the speed of DC motors. One simple method is to varying frequency and voltage of the motor. Another method is controlling SCR for DC motors convert AC power to direct current, with adjustable voltage [3]. In PWM method, pulse width modulation is used to regulate the current sent to the motor. Unlike SCR method which switch at line frequency, PWM controls produce smoother current at higher switching frequencies, typically between 1 and $20 \mathrm{kHz}$ [4].

At $20 \mathrm{kHz}$, the switching frequency is inaudible to humans, thereby eliminating the hum which switching at lower frequency produces. However, some motor controllers for radio controlled models make use of the motor to produce audible sound, most commonly simple beeps. A PWM controller typically contains a large reservoir capacitor and an H-bridge arrangement of

Manuscript received October 3, 2011; revised December 12, 2011.

The authors are with with Islamic University of Technology, Bangladesh (e-mail: riasatkhan87@hotmail.com; e-mail: mdriyadhsharif@gmail.com). switching elements e.g. thyristors, MOSFET, solid state relays, or transistors [5].

PWM is a commonly used technique for controlling power to inertial electrical devices, made practical by modern electronic power switches [6]. The average value of voltage and current fed to the load is controlled by turning the switch between supply and load on and off at a fast pace. The longer the switch is on compared to the off periods, the higher the power supplied to the load is. Duty cycle describes the proportion of 'on' time to the regular interval or 'period' of time; a low duty cycle corresponds to low power, because the power is off for most of the time [7].

In this paper, the basic principles and operation of PWM inverters for ACMC applications using Induction Motor controller devices has been outlined [8]. PIC17C756 microcontroller, TRIAC and DIAC are used to control the speed of the DC motor. The performance of the proposed system in Electronic Workbench software has been evaluated in terms of duty cycle, PWM and output voltage.

\section{INDUCTION MOTORS}

In an induction motor, power is supplied to the rotor by means of electromagnetic induction. If a single phase voltage is applied to the stator, current will start flowing. This current produces a magnetic field $\mathrm{B}_{\mathrm{S}}$, which will rotate in a counter clock wise direction. Speed of the magnetic field's rotation is given by (1),

$$
\mathrm{n}_{\mathrm{sync}}=\frac{120 f}{P}
$$

where $\mathrm{f}$ is the system frequency and $\mathrm{P}$ is the number of poles. This rotating magnetic field $\mathrm{B}_{\mathrm{S}}$ passes over the rotor bars and induces a voltage in them, which is given by (2)

$\mathrm{e}_{\text {ind }}=(\mathbf{v} \times \mathbf{B}) . \mathbf{l}$

where, vis the velocity of the rotor relative to the magnetic field and lis the length of conductor.There will be rotor current flow which would be lagging due to the fact that the rotor has an inductive element. The rotor current will produce a magnetic field at the rotor, $B_{R}$. The interaction between both magnetic field would produce torque according to (3),

$$
\boldsymbol{\tau}_{\text {ind }}=\mathrm{kB}_{\mathrm{R}} \times \mathbf{B}_{\mathrm{S}}
$$

The resulting torque is counter clockwise. Since the rotor induced torque is counter clockwise, the rotor accelerates in that direction. In normal operation both the rotor and stator 
magnetic field $B_{R}$ and $B_{S}$ rotates at synchronous speed, while the rotor itself turns at a slower speed.

The voltage induced in a rotor of an induction motor depends on the speed of rotor relative to the magnetic fields. Slip speed, $\mathrm{n}_{\text {slip }}$ is as the difference between synchronous speed and rotor speed.

$$
\mathrm{n}_{\text {slip }}=\mathrm{n}_{\mathrm{sync}}-\mathrm{n}_{\mathrm{m}}
$$

where, $\mathrm{n}_{\mathrm{m}}$ is mechanical shaft speed of motor. Slip is relative speed expressed on a percentage basis, which is given by (5)

$$
\begin{aligned}
\mathrm{S}=\frac{\mathrm{n}_{\text {slip }}}{n_{\text {sync }}}(\times 100 \%) & \\
= & \frac{n_{\text {sync }}-\mathbf{n}_{m}}{n_{\text {sync }}}(\times 100 \%)
\end{aligned}
$$

If the rotor turns at synchronous speed, $s=0$, while if the rotor is stationary, $\mathrm{s}=1$. All normal motor speeds fall somewhere between those two limits.

\section{TORQUE-SPEED CHARACTERISTICS}

A net magnetic field, $B_{\text {net }}$ is produced by the magnetization current, $I_{M}$. The magnitude of the magnetization current and hence of $B_{\text {net }}$ is directly proportional to the voltage $\mathrm{E}_{1}$. If $\mathrm{E}_{1}$ is constant, then the net magnetic field, $B_{\text {net }}$ in the motor is constant. In an actual motor, $E_{1}$ varies as the load changes, because the stator impedances cause varying voltage drops with varying load. However, these drops in the stator windings are relatively small, so $E_{1}$ is approximately constant with changes in load.

At no load, the rotor slip is very small, and so the relative motion between the rotor and the magnetic field is very small, and rotor frequency is very small. This condition is shown in Fig.1. Since the rotor motion is small, the voltage $E_{R}$ induced in the rotor is very small and the resulting current $I_{R}$ is small. Because the rotor frequency is very small, the reactance of the rotor is nearly zero, and the maximum rotor current $I_{R}$ is almost in phase with the rotor voltage $E_{R}$. The rotor current thus produces a small magnetic field $B_{R}$ at an angle just slightly greater than $90^{\circ}$ behind the net magnetic field, $B_{\text {net. }}$ The induces torque, which keeps the rotor running is given by (6)

$$
\boldsymbol{\tau}_{\text {ind }}=\mathrm{kB}_{\mathrm{R}} \times \mathbf{B}_{\text {net }}
$$

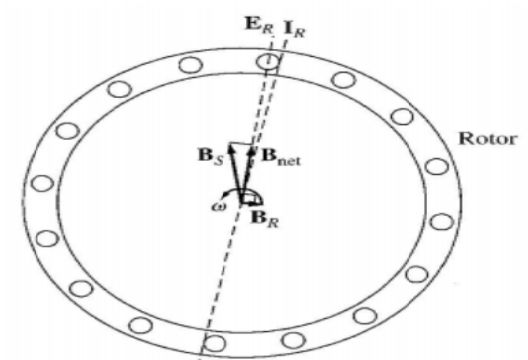

Fig. 1. Magnetic field in an induction under light loads

Since the rotor magnetic field is very small, the induced torque is also quite small. Its magnitude is given by (7)

$$
\boldsymbol{\tau}_{\text {ind }}=\mathrm{kB}_{\mathrm{R}} \mathbf{B}_{\text {net }} \sin \delta
$$

If the load in an induction increases, its slip increases, and the rotor speed falls. Since the rotor speed is slower, there is no more relative motion between the rotor and the stator magnetic fields. Greater relative motion produces a stronger rotor voltage $E_{R}$ which in turn produces a larger rotor current $I_{R}$. With a larger rotor current, rotor magnetic field $B_{R}$ also increases. However the angle of the rotor current and $B_{R}$ changes as well. Since rotor slip is larger, the rotor frequency rises, and rotor reactance increases. The rotor current lags further behind the rotor voltage, and the rotor magnetic field shifts the current. Fig. 2 shows the induction operating at a fairly high load. The increase in $B_{R}$ tends to increase the torque, while increase in angle $\delta$ tends to decrease the torque. The overall induced torque increases to supply the motor's increased load.

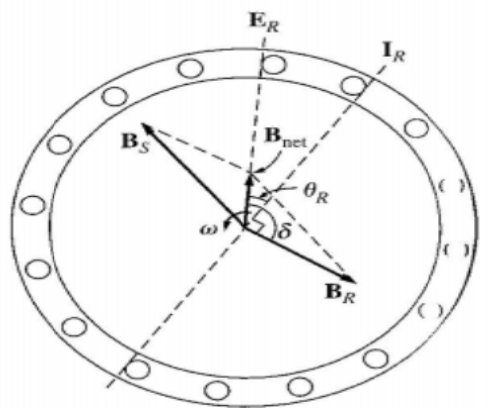

Fig. 2. Magnetic field in an induction under heavy loads

\section{TORQUE-SPEED CURVE}

The induction motor torque-speed characteristics curve is shown is Fig.3. The induced torque of the motor is zero at synchronous speed. The torque-speed curve is nearly linear between no load and full load. There is a maximum possible torque that cannot be exceeded. This torque is pull-out or breakdown torque, is 2 to 3 times the rated full load torque of the motor. The starting torque of the motor is slightly larger than its full load torque, so this motor will start carrying any load that it can supply at full power.

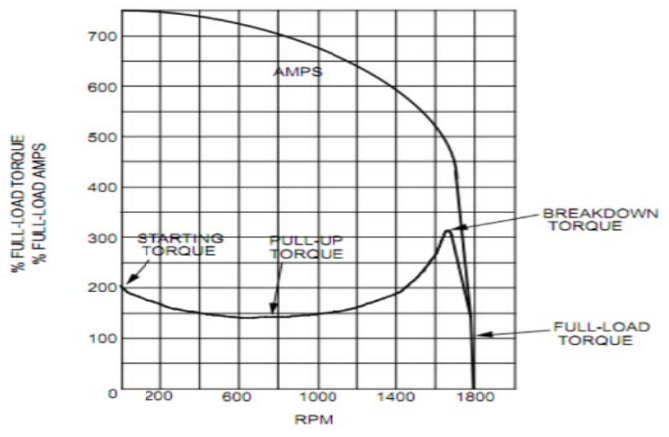

Fig. 3. Induction Motor Torque-Speed Characteristics Curve

The torque on the motor for a given slip varies as the square of the applied voltage. If the rotor of the induction motor is driven faster than synchronous speed, then the direction of the induced torque in the machine reverses. If the motor is turning backward relative to the direction of the magnetic fields, the induced torque will stop the motor very rapidly and will try to rotate it in the other direction. Since reversing the direction of magnetic field rotation is simply a matter of switching any two stator phases. The act of switching two phases in order to stop the motor very rapidly 
is called plugging. The power converted to mechanical form in an induction motor is given by (8)

$$
\mathrm{P}_{\text {conv }}=\tau_{\text {ind }} \omega_{\mathrm{m}}
$$

where, $\omega_{\mathrm{m}}$ is the angular velocity of the motor.

\section{PWM Motor Control}

PWM is a method for binary signals generation, which has two signal periods (high and low).The width, W of each pulse varies between 0 and the period,T.A PWM signal is generated by using the timer and the comparator [9]. The controller constantly checks for zero crossings through the comparator. If the condition is true the output pin will be cleared and the timer will start. The timer counts up to a certain value. If it reaches a predefined value it is stopped and reset for the next cycle. The output pin will also set. This cycle will repeat by waiting for the next zero crossing[10].

\section{Circuit Elements}

PIC17C756 Microcontroller, MAC223A TRIAC, MOC 3011 TRIAC Driver, DIAC, Transformer, Rectifier Bridge, LCD Display, Rewritable Cartridge Fuse, Indicator LightResistor, Capacitor.

\section{Circuit Diagram}

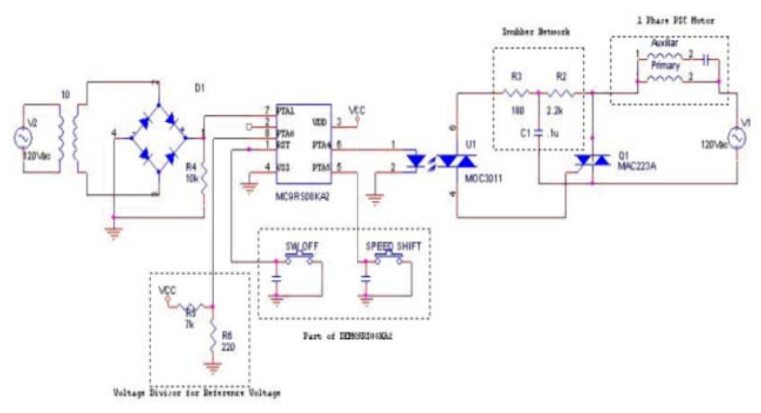

VII. FLOW CHART

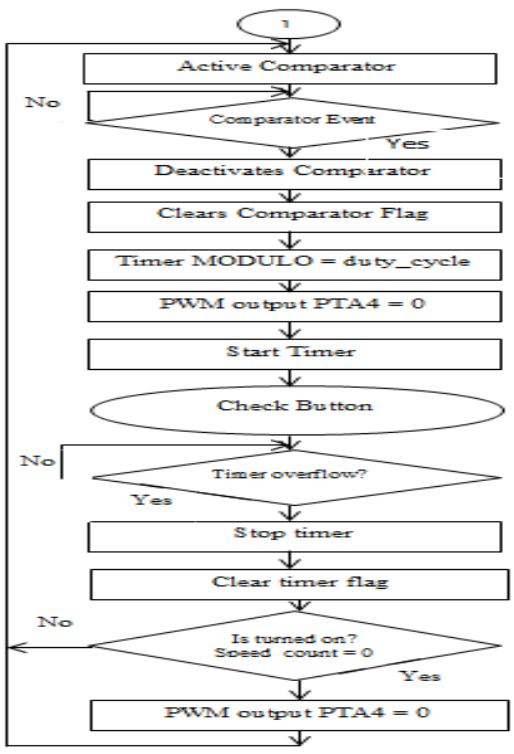

VIII. HARDWARE VIEW

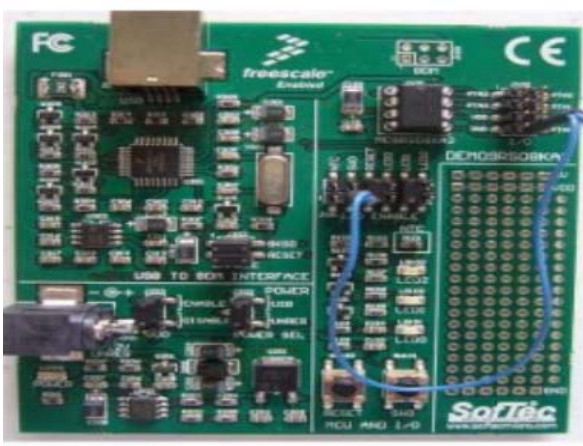

IX. RESUlt

TABLE I:RESULT AT NO-LOAD

\begin{tabular}{llll}
\hline \hline $\begin{array}{l}\text { DIAC } \\
\text { input } \\
\text { voltage }\end{array}$ & $\begin{array}{l}\text { TRIAC } \\
\text { Gate } \\
\text { voltage }\end{array}$ & $\begin{array}{l}\text { Motor } \\
\text { across } \\
\text { voltage }\end{array}$ & Motor speed \\
\hline & & & \\
$2.374 \mathrm{~V}$ & $23.08 \mathrm{mV}$ & $60 \mathrm{~V}$ & $45 \mathrm{RPM}$ \\
$2.459 \mathrm{~V}$ & $23.90 \mathrm{mV}$ & $65 \mathrm{~V}$ & $1460 \mathrm{RPM}$ \\
$2.55 \mathrm{~V}$ & $24.78 \mathrm{mV}$ & $70 \mathrm{~V}$ & $1468 \mathrm{RPM}$ \\
$2.648 \mathrm{~V}$ & $25.73 \mathrm{mV}$ & $80 \mathrm{~V}$ & $1474 \mathrm{RPM}$ \\
$3.130 \mathrm{~V}$ & $30.37 \mathrm{mV}$ & $100 \mathrm{~V}$ & $1480 \mathrm{RPM}$ \\
$3.827 \mathrm{~V}$ & $37.00 \mathrm{mV}$ & $120 \mathrm{~V}$ & $1482 \mathrm{RPM}$ \\
$4.085 \mathrm{~V}$ & $39.43 \mathrm{mV}$ & $150 \mathrm{~V}$ & $1483 \mathrm{RPM}$ \\
$4.704 \mathrm{~V}$ & $45.26 \mathrm{mV}$ & $220 \mathrm{~V}$ & $1483 \mathrm{RPM}$ \\
\hline
\end{tabular}

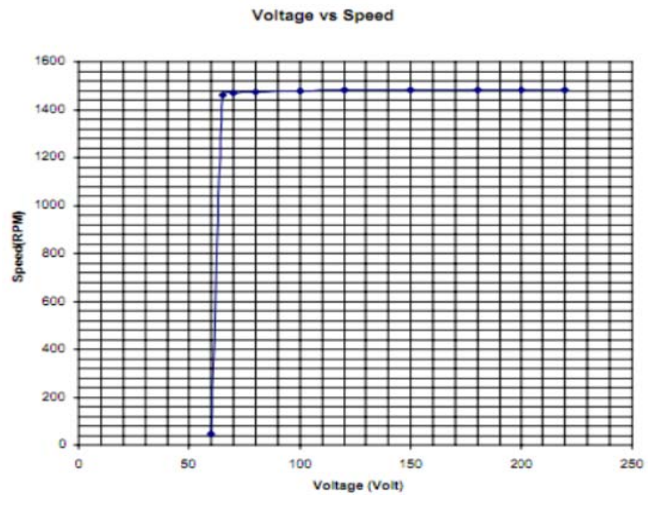

Fig.4. Voltage vs speed at no-load

TABLE II: RESULT AT ON-LOAD

\begin{tabular}{llll}
\hline $\begin{array}{l}\text { DIAC } \\
\text { input } \\
\text { voltage }\end{array}$ & $\begin{array}{l}\text { TRIAC } \\
\text { Gate } \\
\text { voltage }\end{array}$ & $\begin{array}{l}\text { Motor } \\
\text { across } \\
\text { voltage }\end{array}$ & Motor speed \\
\hline & & & \\
$2.374 \mathrm{~V}$ & $23.08 \mathrm{mV}$ & $60 \mathrm{~V}$ & $45 \mathrm{RPM}$ \\
$2.459 \mathrm{~V}$ & $23.90 \mathrm{mV}$ & $65 \mathrm{~V}$ & $414 \mathrm{RPM}$ \\
$2.55 \mathrm{~V}$ & $24.78 \mathrm{mV}$ & $70 \mathrm{~V}$ & $445 \mathrm{RPM}$ \\
$2.648 \mathrm{~V}$ & $25.73 \mathrm{mV}$ & $80 \mathrm{~V}$ & $509 \mathrm{RPM}$ \\
$3.130 \mathrm{~V}$ & $30.37 \mathrm{mV}$ & $100 \mathrm{~V}$ & $636 \mathrm{RPM}$ \\
$3.827 \mathrm{~V}$ & $37.00 \mathrm{mV}$ & $120 \mathrm{~V}$ & $764 \mathrm{RPM}$ \\
$4.085 \mathrm{~V}$ & $39.43 \mathrm{mV}$ & $150 \mathrm{~V}$ & $955 \mathrm{RPM}$ \\
$4.704 \mathrm{~V}$ & $45.26 \mathrm{mV}$ & $220 \mathrm{~V}$ & $1400 \mathrm{RPM}$ \\
\hline \hline
\end{tabular}




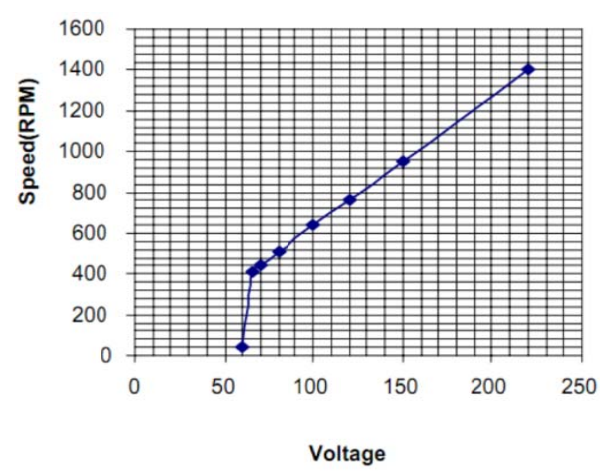

Fig. 5. Voltage vs speed at no-load

\section{InPUT-OUTPUT WAVEFORM}
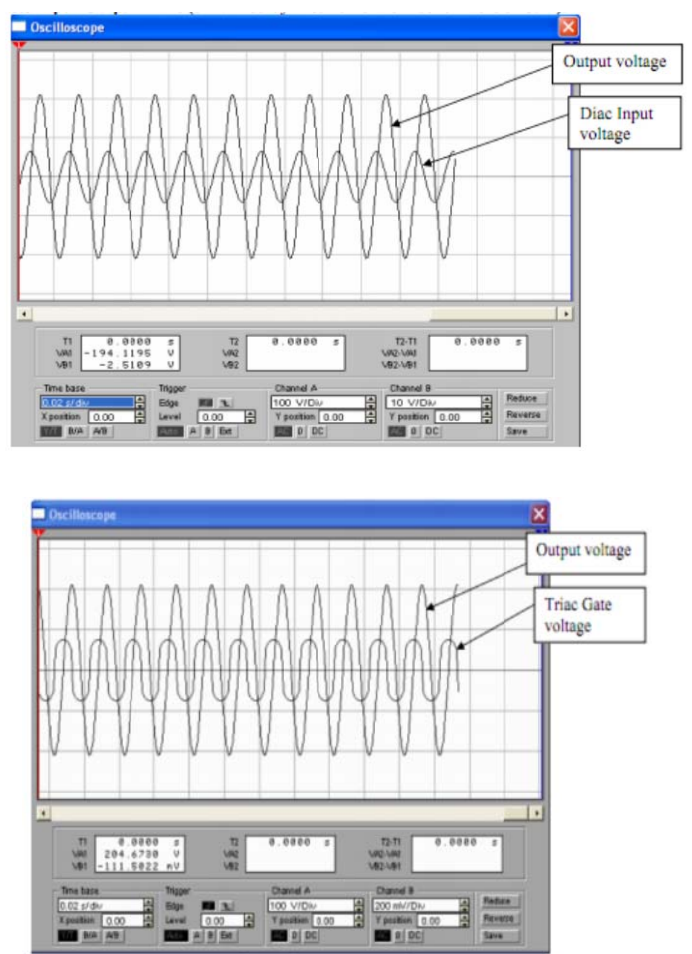

\section{CONCLUSIONS}

In this paper, microcontroller PIC17C756 has been used for PWM adjustable speed control. The circuit can be divided in three modules. The first module is the transformer and rectifier. At the end of this stage there is a rectified $\mathrm{AC}$ wave at $120 \mathrm{~Hz}$ at half of the original voltage peak-peak. The next module is zero cross detection circuit. To test this module MCU is needed with program running [8]. The designated output pin of the MCU is expected to have a pulse at $120 \mathrm{~Hz}$. MOC and TRIAC are the last modules.TRIAC has three terminals (MT1, MT2 and Gate). Its voltage drop across MT1 and MT2 can be controlled by controlling its gate voltage. In the circuit gate is controlled by DIAC. DIAC input is controlled by an $\mathrm{R}-\mathrm{C}$ triggering circuit [9]. In triggering circuit there is a variable Resistor to vary TRIAC gate voltage trough DIAC. As TRIAC is connected in series with Motor input so, if TRIAC MT1MT2 across drop increases Motor input voltage decreases and if TRIAC MT1-MT2 across drop decreases motor input voltage increases. When the motor runs at no-load, rated RPM reaches at $65 \mathrm{~V}$ only. When the motor runs at load, RPM reaches at rated value gradually.Electronic Workbench software has been used to evaluate the results. By hardware implementation and program the two approaches the same result. The proposed system can avoid non linearity problems on speed control and mechanical speed variation.

\section{FUTURE WORKS}

Mathematical model can be obtained from the graph of the motor speed response. From the mathematical model, using MATLAB improved motor speed can be obtained by using controller package e.g. PID controller, fuzzy logic controller, etc. Higher voltage and power can also be obtained by using IGBT. Fully automatic PLC based speed controller also can be designed for better reliability.

\section{REFERENCES}

[1] S. J. Chapman, Electric Machinery Fundamentals, McGraw-Hill, 2005, pp. 381-385

[2] V. K. Mehta and R. Mehta, Objective Electrical Technology, S.Chand, 2007, pp. 637-638.

[3] I. M. Gottlieb, Electric Motors and Control Techniques, McGrawHill, February 1, 1994.

[4] I. M. Gottlieb, Practical Electric Motor Handbook, Newnes, October 8, 1997.

[5] F. B. Crocker and M. Arendt, Electric motors, their action, control and application, New York, D. Van Nostrand Company.

[6] B. P. Lathi,Modern Digital and Analog Communication Systems, Oxford University Press, 2007, pp. 260-263.

[7] http://en.wikipedia.org/wiki/Duty cycle.

[8] J. A. Houldsworth and W.B. Rosink, Introduction to PWM Speed Control System for Three Phase AC motors, Electronic Components and ications, Vol.2, No.2, February 1980.

[9] D.A.Grant, J.A.Houldsworth, K.N.Lower, "A new high-quality PWM AC drive," IEEE Transactions, Vol. IA-19, No 2, 1983.

[10] J.E.Gilliam, J.A.Houldsworth, L.Hadley, "Variable Speed Induction Motor with Integral Ultrasonic PWM Inverter," IEEE Conference, APEC,pp. 92-96,1988.

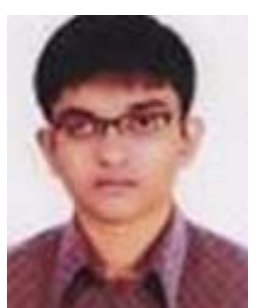

R. Khan received B.Sc in Electrical and Electronic Engineering from Islamic University of Technology (IUT) in 2010. He is student of M.Sc Eng. In the institute of Renewable Energy of University of Dhaka. Currently, He is working as a lecturer in Electrical and Electronic Engineering department of Green University of Bangladesh. His research interests include power systems, power electronics and renewable energy.

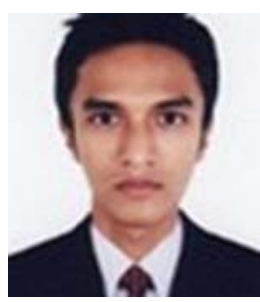

M. M. S. Riyadhreceived B.Sc in Electrical and Electronic Engineering from Islamic University of Technology (IUT) in 2010. He worked at Huawei Technologies (BD) Ltd. as a BSS Engineer. Now, he is serving as a Lecturer in Electrical and Electronic Engineering department of University of Information Technology and Sciences (UITS). His research interests include power electronics, biomedical imaging, LTE technology. 